\title{
Circadian Rhythms and Social Media Information-Sharing
}

\author{
Gleasure, Rob
}

Document Version

Accepted author manuscript

Published in:

Information Systems and Neuroscience

DOI:

10.1007/978-3-030-28144-1_1

Publication date:

2020

License

Unspecified

Citation for published version (APA):

Gleasure, R. (2020). Circadian Rhythms and Social Media Information-Sharing. In F. D. Davis, R. Riedl, J. vom Brocke, P-M. Léger, A. Randolph, \& T. Fischer (Eds.), Information Systems and Neuroscience: NeurolS Retreat 2019 (pp. 1-11). Springer. Lecture Notes in Information Systems and Organisation Vol. 32 https://doi.org/10.1007/978-3-030-28144-1_1

Link to publication in CBS Research Portal

\section{General rights}

Copyright and moral rights for the publications made accessible in the public portal are retained by the authors and/or other copyright owners and it is a condition of accessing publications that users recognise and abide by the legal requirements associated with these rights.

Take down policy

If you believe that this document breaches copyright please contact us (research.lib@cbs.dk) providing details, and we will remove access to the work immediately and investigate your claim. 


\section{Circadian Rhythms and Social Media Information-Sharing Rob Gleasure}

Article in proceedings (Accepted version*)

\section{Please cite this article as:}

Gleasure, R. (2020). Circadian Rhythms and Social Media Information-Sharing. In F. D. Davis, R. Riedl, J. vom Brocke, P-M. Léger, A. Randolph, \& T. Fischer (Eds.), Information Systems and Neuroscience: NeurolS Retreat 2019(pp. 1-11). Cham: Springer. Lecture Notes in Information Systems and Organisation, Vol.. 32 https://doi.org/10.1007/978-3-030-28144-1_1

This is a post-peer-review, pre-copyedit version of an article published in Information Systems and Neuroscience: NeurolS Retreat 2019. The final authenticated version is available online at: DOI: https://doi.org/10.1007/978-3-030-28144-1_1

* This version of the article has been accepted for publication and undergone full peer review but has not been through the copyediting, typesetting, pagination and proofreading process, which may lead to differences between this version and the publisher's final version AKA Version of Record. 


\title{
Circadian rhythms and social media information-sharing
}

\author{
Rob Gleasure \\ Department of Digitalization, Copenhagen Business School, Copenhagen, Denmark \\ rg.digi@cbs.dk
}

\begin{abstract}
Large amounts of information are shared through social media. Such communication assumes users are sufficiently aligned, not only in terms of their interests but also in terms of their emotional and cognitive states. It is not clear how this emotional and cognitive alignment is achieved for social media, given one-to-one interactions are infrequent and discussion often spans loosely connected individuals. This study argues that circadian rhythms play an important physiological role in aligning users for information-sharing, as information shared at different times of the day is likely to encounter users with common physiological states. Data are gathered from Twitter to examine patterns of sentiment and text complexity in social media, as well as how these patterns affect information-sharing. Results suggest the timing of a social media post, relative to collective patterns of sentiment and text complexity, is a better predictor of information-sharing than the sentiment and text complexity of the post itself. Put differently, information is more likely to be shared when it is posted at times of the day when other users are primed for emotion and concentration, independent of whether that posted information is itself emotional or demanding in concentration.
\end{abstract}

Keywords: Circadian. Social Media. Sentiment. Text Complexity. Twitter.

\section{Introduction}

Social media provides an important means of gathering and distributing information. Yet the sheer volume of information limits what individuals can consume and share, i.e. the amount of information users may 'convey' significantly exceeds the amount of information upon which they may 'converge' [c.f. 9]. Key determinants of convergence and information-sharing have been identified as sentiment $[14,35]$ and text complexity $[27,34]$. These qualities influence a recipient's motivation and capability to engage with particular pieces of information. The influence of sentiment and text complexity on information-sharing is not absolute; rather, their impact depends on their alignment with the needs of recipients at some particular time. Failure to match the sentiment of recipients may result in posts appearing out of sync or 'tone deaf' [4, 36]. Similarly, more complex information is often less welcome when discussion is adversarial $[27,34]$ and more welcome when discussion is collaborative $[8,16,19]$. 
This need for alignment between communicators and recipients is typically developed over the course of one-to-one symbolic interactions [3] and physiological mirroring [29]. Yet social media-based information-sharing is rarely one-to-one and often occurs between individuals who do not frequently interact [13]. Hence it is not obvious how users achieve the alignment to interact effectively.

This study proposes the alignment of social media users relies partly on common circadian rhythms, i.e. daily light-entrained physiological oscillations that help to ensure individuals are most active during the day and most restful at night $[1,6]$. Studies have shown circadian rhythms produce predictable patterns in the sentiment of social media posts. Notably, an extensive study by Macy and Golder [15] found consistent circadian patterns in social media sentiment across countries, seasons, and days of the week. Previous research has also shown that information-sharing on social media is disproportionally between individuals in geographical proximity [38], hence in similar time zones. Thus, there is an intuitive role for circadian rhythms as a mechanism for creating alignment between social media users.

\section{Social Media and Circadian Rhythms}

Circadian rhythms encourage us to be active at the times best suited for our environment, e.g. to crave food and increase in activity when food sources are typically plentiful [33]. Circadian rhythms regulate a range of biological processes, from hormonal changes, to body temperature, to mood $[1,25,26,32,33]$. These roughly 24hour cycles are coded into the cells of most living things, creating a natural clock that oscillates between wakefulness and restfulness - even when environments are artificially manipulated to make days seem longer or shorter $[1,2,7]$.

For mammals such as humans, daily circadian cycles are entrained by light through the suprachiasmatic nucleus ( $\mathrm{SCN}$ ), which fires to dorsomedial areas of the hypothalamus and links to neural pathways involved in the release of mood and effort-related hormones such dopamine [21], serotonin [33], and cortisol [10]. The SCN simultaneously inhibits the pineal gland from secreting melatonin, the hormone that accumulates to promote sleep states [2]. This results in dual-process cycle (see [33]) where (i) the ascending arousal system triggers hormones to promote activity/inhibit the release of sleep-inducing melatonin via the pineal gland, while (ii) the competing homeostatic sleep system gradually builds up pressure until it can overwhelm sleep-inhibitors and produce enough melatonin to inhibit the SCN, resulting in a 'flip flop' switch between wake-sleep transitions. A summary of documented daily circadian hormonal patterns is illustrated in Figure 1. 


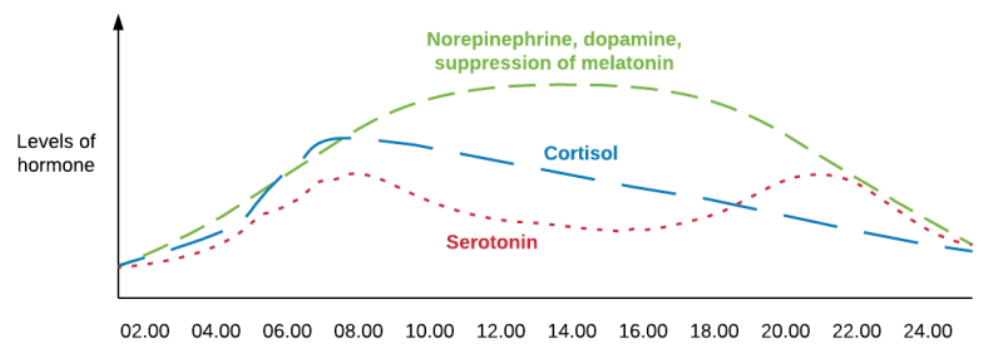

Fig. 1. Typical circadian levels of dopamine, serotonin, cortisol, and melatonin suppression.

The role of these hormones in regulating engagement and energy means these patterns are relevant for social media information-sharing in two ways.

First, increased engagement and energy are linked to higher levels of emotional affect [37]. Hence circadian rhythms tend to influence the mood of individuals at different times of the day in a way that harmonizes that mood with other social actors [25], even in where no interaction has occurred.

Second, increased engagement and energy are associated with an individual's willingness to engage in challenging behaviors [18]. Communication via social media changes the nature of communication, wherein individuals must decide which communications to ignore, which to prioritize, and which to share with others [22, 30]. More complex communications increase mental load for the recipient [31], increasing the pressure on specific intrinsic and extrinsic rewards [23].

Circadian hormone patterns have been used to predict collective shifts in mood and information-processing in social media use. This includes daily contribution patterns to Wikipedia [39], seasonal changes in depression-related information search [11], and changes in word volume variation [12]. Most comprehensively, Golder and Macy [15] found strikingly consistent daily sentiment patterns on Twitter across countries, seasons, and days of the week.

Thus, circadian rhythms may conceivably have a direct impact on the sentiment and text complexity of social media posts, as well as subsequent information-sharing behaviors of users (as users will be in different, common physiological states at different times of the day). It may further moderate the relationship between sentiment/text complexity and information-sharing by extending alignment between the communicator and the recipients.

\section{Method}

Data were gathered from Twitter Data on $8^{\text {th }}$ August and $6^{\text {th }}$ December 2018. For both dates, 1,000 English-language tweets were gathered from US social media users in each of the 50 states at 1-hour intervals (total $\mathrm{N}=2,400,000$ ). Duplicates and retweets were removed, as were tweets from private accounts or accounts with no followers, and tweets with no text. Sentiment for each tweet was analyzed at a word level 
using the AFINN sentiment lexicon for microblogs [28], accessed through the tidytext library $^{1}$ for $\mathrm{R}$ (an open source data processing platform). Sentiment was scored according to positive affect (PA), negative affect (NA), valence (PA-NA) and arousal (PA+NA). Tweets with no scores for sentiment were removed to allow analysis to focus on discussion with some emotional content. This resulted in a final set of 404,946 tweets. Text complexity was then scored using the Gunning FOG index [17], the Dale-Chall measure [5] (later dropped for convergence issues), the Flesch-Kincaid Reading Ease Index (FRE) [20], and the Simple Measure Of Gobbledygook (SMOG) [24] (accessed via the quanteda library ${ }^{2}$ ).

\section{$4 \quad$ Findings}

Data show reliable circadian patterns of sentiment and text complexity, consistent with existing research (see Figures 2 and 3) [c.f. 15]. The predicted sentiment and text complexity at different times were estimated using separate locally weighted regression (LOESS) curves for each measure of sentiment and text complexity. These curves were tested against the patterns and effect size of comparative polynomials to ensure reliability. A series of negative binomial regressions (see Tables 1 and 2) also compared the impact of a tweet's sentiment and text complexity with the predicted sentiment and text complexity based on the time of day it was posted, i.e. the qualities of the tweet vs. the daily aggregate qualities of Twitter discussion at the time of posting. Hierarchical models were introduced that predicted information-sharing by adding the sentiment/text complexity of a tweet (model 1), then the circadian predicted sentiment/text complexity at the time that tweet was posted (model 2), then finally the interaction term (model 3).

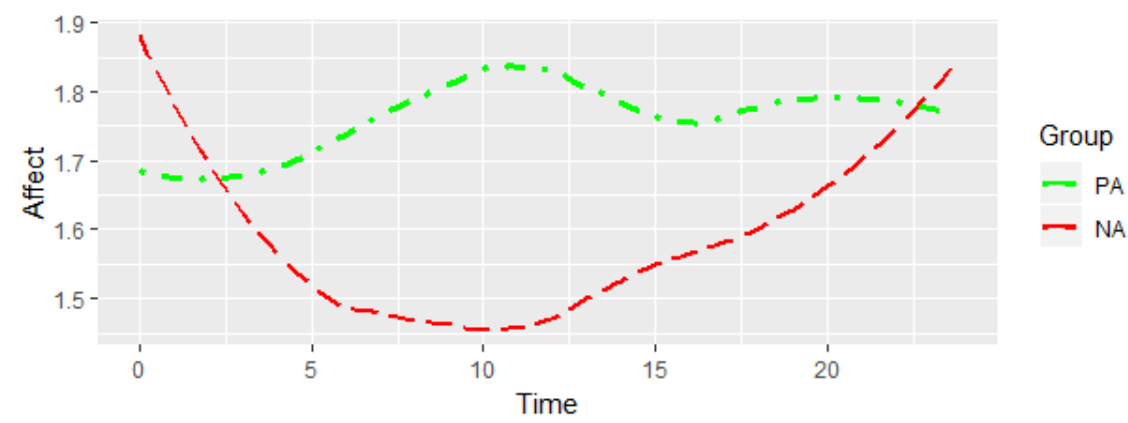

Fig. 2. LOESS curves for positive affect $(P A)$ and negative affect $(N A)$ based on avg. sentiment for time

\footnotetext{
${ }^{1}$ Tidytext version 0.1 .8 , available at https://cran.r-project.org/web/packages/tidytext/index.html ${ }^{2}$ quanteda ver. 1.3.4, available at https://cran.r-project.org/web/packages/quanteda/index.html
} 
Table 1. Results of negative binomial regression for circadian predicted sentiment on retweets

\begin{tabular}{|c|c|c|c|c|c|c|c|c|c|}
\hline & \multicolumn{3}{|c|}{ Model 1} & \multicolumn{3}{|c|}{ Model 2} & \multicolumn{3}{|c|}{ Model 3} \\
\hline & $B$ & $S E$ & $\exp$ & $b$ & $S E$ & $\exp$ & $B$ & $S E$ & Exp \\
\hline Arousal & $.026 * *$ & .006 & 1.026 & $.024 * * *$ & .006 & 1.024 & $-.531 * *$ & .189 & .588 \\
\hline PredictedArousal & & & & $.817 * * *$ & .134 & 2.257 & Ns & - & - \\
\hline Ar*PredictedAr & & & & & & & $-.165^{* *}$ & .056 & .848 \\
\hline Hashtags & $.131 * * *$ & .014 & & $.135 * * *$ & .014 & & $.135 * * *$ & .141 & \\
\hline Mentions & $-.291 * * *$ & .018 & & $-.289 * * *$ & .018 & & $-.289 * * *$ & .178 & \\
\hline Urls & $.319^{* * *}$ & .025 & & $.336 * * *$ & .025 & & $.335 * * *$ & .025 & \\
\hline Log(followers) & $.557 * * *$ & .009 & & $.559 * * *$ & .009 & & $.559 * * *$ & .009 & \\
\hline Log(activity) & $-.179 * * *$ & .009 & & $-.181 * * *$ & .009 & & $-.181 * * *$ & .009 & \\
\hline AIC & \multicolumn{3}{|c|}{77604} & \multicolumn{3}{|c|}{77563} & \multicolumn{3}{|c|}{77563} \\
\hline Valence & $-.011 * *$ & .004 & .989 & -.010 & .004 & .990 & Ns & - & - \\
\hline PredictedValence & & & & $-1.122 * * *$ & .101 & .320 & $-1.118 * * *$ & .101 & .321 \\
\hline Val*PredictedVal & & & & & & & Ns & - & - \\
\hline Hashtags & $.131 * * *$ & .014 & & $.133^{* * *}$ & .014 & & $.133^{* * *}$ & .014 & \\
\hline Mentions & $-.291 * * *$ & .018 & & $-.285 * * *$ & .018 & & $-.285 * * *$ & .018 & \\
\hline Urls & $.312 * * *$ & .025 & & $.339 * * *$ & .025 & & $.339 * * *$ & .025 & \\
\hline Log(followers) & $.557 * * *$ & .009 & & $.562 * * *$ & .009 & & $.563 * * *$ & .009 & \\
\hline Log(activity) & $-.181 * * *$ & .009 & & $-.187 * * *$ & .009 & & $-.188 * * *$ & .009 & \\
\hline AIC & \multicolumn{3}{|c|}{77615} & \multicolumn{3}{|c|}{77492} & \multicolumn{3}{|c|}{77492} \\
\hline PA & $\mathrm{ns}$ & - & - & $\mathrm{ns}$ & - & & Ns & - & - \\
\hline PredictedPA & & & & $-2.785 * * *$ & .296 & .053 & $-2.469 * * *$ & .399 & .075 \\
\hline PA*PredictedPA & & & & & & & $\mathrm{Ns}$ & - & - \\
\hline Hashtags & $.128^{* * *}$ & .014 & & $.123 * * *$ & .014 & & $.123 * * *$ & .014 & - \\
\hline Mentions & $-.294 * * *$ & .018 & & $-.288^{* * *}$ & .018 & & $-.288 * * *$ & .018 & \\
\hline Urls & $.308^{* * *}$ & .025 & & $.309 * * *$ & .025 & & $.309 * * *$ & .025 & \\
\hline $\log$ (followers) & $.556^{* * * *}$ & .009 & & $.559 * * *$ & .009 & & $.559 * * *$ & .009 & \\
\hline $\log$ (activity) & $-.179 * * *$ & .009 & & $-.185^{* * *}$ & .009 & & $-.185^{* * *}$ & .009 & \\
\hline AIC & \multicolumn{3}{|c|}{77623} & \multicolumn{3}{|c|}{77535} & \multicolumn{3}{|c|}{77535} \\
\hline NA & $.029 * * *$ & .069 & 1.029 & $.027 * * *$ & .006 & 1.027 & $\mathrm{Ns}$ & - & - \\
\hline PredictedNA & & & & $1.182^{* * *}$ & .122 & 3.277 & $1.159 * * *$ & .153 & 3.218 \\
\hline NA*PredictedNA & & & & & & & $\mathrm{Ns}$ & - & - \\
\hline Hashtags & $.134 * * *$ & .014 & & $.138 * * *$ & .014 & & $.138 * * *$ & .014 & - \\
\hline Mentions & $-.287 * * *$ & .018 & & $-.285^{* * *}$ & .018 & & $-.285^{* * * *}$ & .018 & \\
\hline Urls & $.319^{* * *}$ & .025 & & $.346^{* * * *}$ & .025 & & $.346^{* * *}$ & .025 & \\
\hline Log(followers) & $.558 * * *$ & .009 & & $.563 * * *$ & .009 & & $.563 * * *$ & .009 & \\
\hline $\log$ (activity) & $-.182 * * *$ & .009 & & $-.186^{* * *}$ & .009 & & $-.186 * * *$ & .009 & \\
\hline AIC & \multicolumn{3}{|c|}{77602} & \multicolumn{3}{|c|}{77512} & \multicolumn{3}{|c|}{77514} \\
\hline
\end{tabular}

$* \mathrm{p}<.05, * * \mathrm{p}<.01, * * * \mathrm{p}<.001, \dagger \mathrm{p}<.1$, ns $=$ not significant 
Table 2. Results of negative binomial regression for circadian predicted sentiment on retweets

\begin{tabular}{|c|c|c|c|c|c|c|c|c|c|}
\hline & \multicolumn{3}{|c|}{ Model 1} & \multicolumn{3}{|c|}{ Model 2} & \multicolumn{3}{|c|}{ Model 3} \\
\hline & $B$ & $S E$ & $\exp$ & $b$ & $S E$ & $\operatorname{Exp}$ & $B$ & $S E$ & $\operatorname{Exp}$ \\
\hline FOG & .017 *** & .003 & 1.017 & $.012 * * *$ & .003 & 1.012 & ns & - & \\
\hline LOESS FOG. & & & & $-.259 * * *$ & .046 & 1.308 & $-.238 * *$ & .084 & 1.287 \\
\hline FOG*LOESS & & & & & & & ns & - & \\
\hline Hashtags & $.129 * * *$ & .014 & & $.133 * * *$ & .014 & & $.133 * * *$ & .141 & \\
\hline Mentions & $-.288 * * *$ & .018 & & $-.287 * * *$ & .018 & & $-.287 * * *$ & .178 & \\
\hline Urls & $.286^{* * * *}$ & .025 & & $.303 * * *$ & .025 & & $.303 * * *$ & .025 & \\
\hline Log(followers) & $.553 * * *$ & .009 & & $.555^{* * *}$ & .009 & & $.555^{* * *}$ & .009 & \\
\hline Log(activity) & $-.178 * * *$ & .009 & & $-.179 * * *$ & .009 & & $-.179 * * *$ & .009 & \\
\hline AIC & \multicolumn{3}{|c|}{77603} & \multicolumn{3}{|c|}{77574} & \multicolumn{3}{|c|}{77576} \\
\hline FRE & $.018^{* * * *}$ & .003 & 1.018 & $.019 * * *$ & .003 & 1.019 & ns & - & \\
\hline LOESS FRE & & & & $-.251 * * *$ & .049 & 1.299 & $-.229 * *$ & .079 & 1.267 \\
\hline FRE*LOESS & & & & & & & ns & - & \\
\hline Hashtags & $.132 * * *$ & .014 & & $.136^{* * *}$ & .014 & & $.136^{* * * *}$ & .014 & \\
\hline Mentions & $-.285^{* * *}$ & .018 & & $-.284 * * *$ & .018 & & $-.285 * * *$ & .018 & \\
\hline Urls & $.279^{* * *}$ & .025 & & $.294 * * *$ & .025 & & $.294^{* * * *}$ & .025 & \\
\hline Log(followers) & $.552 * * *$ & .009 & & $.554 * * *$ & .009 & & $.554 * * *$ & .009 & \\
\hline Log(activity) & $-.177 * * *$ & .009 & & $-.178 * * *$ & .009 & & $-.178 * * *$ & .009 & \\
\hline AIC & \multicolumn{3}{|c|}{77594} & \multicolumn{3}{|c|}{77570} & \multicolumn{3}{|c|}{77572} \\
\hline SMOG & $.015 * * *$ & .004 & 1.015 & $.016 * * *$ & .004 & 1.016 & ns & - & \\
\hline LOESS SMOG & & & & $-.372 * * *$ & .055 & 1.464 & $-.338^{* *} *$ & .125 & 1.416 \\
\hline SMOG *LOESS & & & & & & & ns & - & \\
\hline Hashtags & $.131 * * *$ & .014 & & $.135^{* * *}$ & .014 & & $.135^{* * *}$ & .014 & \\
\hline Mentions & $-.289 * * *$ & .018 & & $-.288 * * *$ & .018 & & $-.288 * * *$ & .018 & \\
\hline Urls & $.286 * * *$ & .025 & & $.305^{* * *}$ & .025 & & $.305^{* * *}$ & .025 & \\
\hline Log(followers) & $.552 * * *$ & .009 & & $.555^{* * * *}$ & .009 & & $.555^{* * *}$ & .009 & \\
\hline Log(activity) & $-.177 * * *$ & .009 & & $-.179 * * *$ & .009 & & $-.179 * * *$ & .009 & \\
\hline AIC & \multicolumn{3}{|c|}{77609} & \multicolumn{3}{|c|}{77567} & \multicolumn{3}{|c|}{77569} \\
\hline
\end{tabular}

$* \mathrm{p}<.05, * * \mathrm{p}<.01, * * * \mathrm{p}<.001, \dagger \mathrm{p}<.1$, ns $=$ not significant

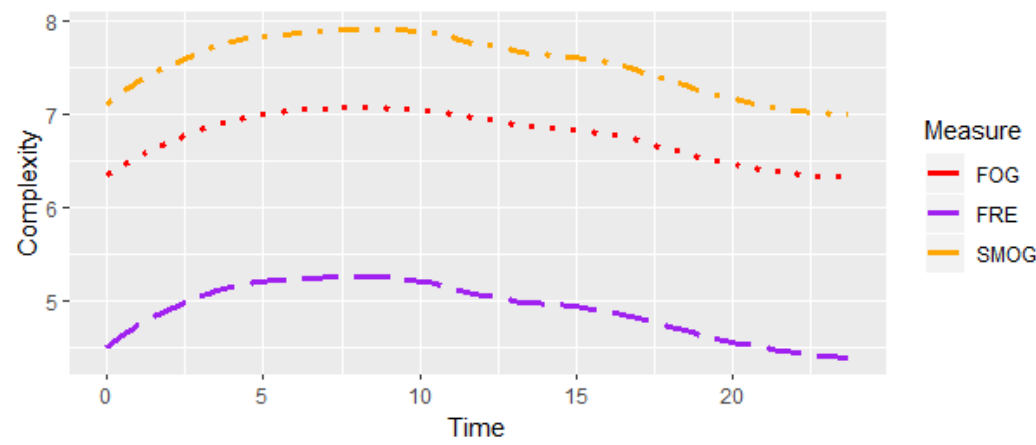

Fig. 3. LOESS curves for FOG, FRE, and SMOG, based on avg. text complexity for time 


\section{Discussion}

Findings from this study support previous observations of circadian patterns in the sentiment of social media discussion. They also extend these patterns to text complexity, the first study to do so, to the author's knowledge.

More importantly, findings from this study suggest collective circadian patterns of sentiment and text complexity provide stronger predictions of information-sharing than the sentiment and text complexity of individual posts. Put differently, information is more likely to be shared when it is posted at times of the day when other users are primed for emotion and concentration, independent of whether that posted information is itself emotional or demanding in concentration.

More broadly, this study provides an explanatory physiological mechanism for how loosely connected individuals can achieve the emotional and cognitive alignment required for information-sharing. This has obvious practical implications for social media, e.g. perhaps posted information should be delayed for users in other time zones. However, this finding also has implications beyond social media discussion. For example, the circadian model proposed in this study may help to explain communication and relationship-building difficulties in distributed organizational teams.

\section{References}

1. Aschoff, J. Circadian rhythms in man. Science, 148, 3676 (1965), 1427-1432.

2. Bell-Pedersen, D., Cassone, V. M., Earnest, D. J., Golden, S. S., Hardin, P. E., Thomas, T. L., \& Zoran, M. J. Circadian rhythms from multiple oscillators: lessons from diverse organisms. Nature Reviews Genetics, 6, 7 (2005), 544-556.

3. Blumer, H. Symbolic interactionism: Perspective and method. University of California Press (1986).

4. Bollen, J., Mao, H., \& Zeng, X. Twitter mood predicts the stock market. Journal of Computational Science, 2, 1 (2011), 1-8.

5. Chall, J. S., \& Dale, E. Readability revisited: The new Dale-Chall readability formula. Brookline Books, Massachusetts (1995).

6. Crowley, S. J., Acebo, C., \& Carskadon, M. A. Sleep, circadian rhythms, and delayed phase in adolescence. Sleep Medicine, 8, 6 (2007), 602-612.

7. Czeisler, C. A., Shanahan, T. L., Klerman, E. B., Martens, H., Brotman, D. J., Emens, J. S., ... \& Rizzo, J. F. Suppression of melatonin secretion in some blind patients by exposure to bright light. New England Journal of Medicine, 332, 1 (1995), 6-11.

8. Dabbagh, N., \& Kitsantas, A. Personal Learning Environments, social media, and selfregulated learning: A natural formula for connecting formal and informal learning. The Internet and Higher Education, 15, 1 (2012), 3-8.

9. Dennis, A. R., Fuller, R. M., \& Valacich, J. S. Media, tasks, and communication processes: A theory of media synchronicity. MIS Quarterly, 32, 3 (2008), 575-600.

10. Dimitrov, S., Benedict, C., Heutling, D., Westermann, J., Born, J., \& Lange, T. Cortisol and epinephrine control opposing circadian rhythms in T cell subsets. Blood, 113, 21 (2009), 5134-5143. 
11. Dzogang, F., Lansdall-Welfare, T., \& Cristianini, N. Seasonal Fluctuations in Collective Mood Revealed by Wikipedia Searches and Twitter Posts. IEEE international conference on data mining workshop (SENTIRE), Barcelona (2016).

12. Dzogang, F., Lightman, S., \& Cristianini, N. Circadian mood variations in Twitter content. Brain and Neuroscience Advances, 1 (2017), 1-14.

13. Enjolras, B., Steen-Johnsen, K., \& Wollebæk, D. Social media and mobilization to offline demonstrations: Transcending participatory divides? New Media \& Society, 15, 6 (2013), 890-908.

14. Ferrara E, \& Yang Z. Quantifying the effect of sentiment on information diffusion in social media. PeerJ Computer Science, 1, e26 (2015), https://doi.org/10.7717/peerj-cs.26.

15. Golder, S. A., \& Macy, M. W. Diurnal and seasonal mood vary with work, sleep, and daylength across diverse cultures. Science, 333, 6051 (2011), 1878-1881.

16. Guille, A., Hacid, H., Favre, C., \& Zighed, D. A. Information diffusion in online social networks: A survey. ACM Sigmod Record, 42, 2 (2013), 17-28.

17. Gunning, R. The technique of clear writing. McGraw-Hill, UK (1952).

18. Kahn, W. A. Psychological conditions of personal engagement and disengagement at work. Academy of Management Journal, 33, 4 (1990), 692-724.

19. Korda, H., \& Itani, Z. Harnessing social media for health promotion and behavior change. Health Promotion Practice, 14, 1 (2013), 15-23.

20. Kincaid, J. P., Fishburn, R. P., Rogers, R.L., \& Chissom, B.S. Derivation of new readability formulas for navy enlisted personnel. Technical Report Research Branch Report 8-75, Millington, Tennesse, Naval Air Station (1975).

21. Korshunov, K. S., Blakemore, L. J., \& Trombley, P. Q. Dopamine: a modulator of circadian rhythms in the central nervous system. Frontiers in Cellular Neuroscience, 11, 91 (2017), 1-17.

22. Lee, S. K., Lindsey, N. J., \& Kim, K. S. The effects of news consumption via social media and news information overload on perceptions of journalistic norms and practices. Computers in Human Behavior, 75 (2017), 254-263.

23. Lee, W., Reeve, J., Xue, Y., \& Xiong, J. Neural differences between intrinsic reasons for doing versus extrinsic reasons for doing: An fMRI study. Neuroscience Research, 73, 1 (2012), 68-72.

24. McLaughlin, G. H. SMOG grading-a new readability formula. Journal of Reading, 12, 8 (1969), 639-646.

25. McClung, C. A. Circadian genes, rhythms and the biology of mood disorders. Pharmacology \& Therapeutics, 114, 2 (2007), 222-232.

26. Murray, G., Nicholas, C. L., Kleiman, J., Dwyer, R., Carrington, M. J., Allen, N. B., \& Trinder, J. Nature's clocks and human mood: The circadian system modulates reward motivation. Emotion, 9, 5 (2009), 705-716.

27. Murthy, D. Twitter: Microphone for the masses? Media, Culture \& Society, 33, 5 (2011), 779-789.

28. Nielsen, F. A. A new ANEW: Evaluation of a word list for sentiment analysis in microblogs. ESWC2011 Workshop on 'Making Sense of Microposts': Big things come in small packages, Heraklion, Crete (2011).

29. Neumann, R., \& Strack, F. "Mood contagion": the automatic transfer of mood between persons. Journal of Personality and Social Psychology, 79, 2 (2000), 211-223.

30. Oeldorf-Hirsch, A., \& Sundar, S. S. Posting, commenting, and tagging: Effects of sharing news stories on Facebook. Computers in Human Behavior, 44, 240-249. 
31. Petty, R. E., \& Cacioppo, J. T. The elaboration likelihood model of persuasion. In L. Berkowitz (Ed.), Advances in experimental social psychology (pp. 123-205), Academic Press, New York (1986).

32. Pontes, A. L. B. D., Engelberth, R. C. G. J., Nascimento Jr, E. D. S., Cavalcante, J. C., Costa, M. S. M. D. O., Pinato, L., ... \& Cavalcante, J. D. S. Serotonin and circadian rhythms. Psychology \& Neuroscience, 3, 2 (2010), 217-228.

33. Saper, C. B., Scammell, T. E., \& Lu, J. Hypothalamic regulation of sleep and circadian rhythms. Nature, 437, 7063 (2005), 1257-1263.

34. Speed, E., \& Mannion, R. The rise of post-truth populism in pluralist liberal democracies: challenges for health policy. International Journal of Health Policy and Management, 6, 5 (2017), 249-251.

35. Stieglitz, S., \& Dang-Xuan, L. Emotions and information diffusion in social mediasentiment of microblogs and sharing behavior. Journal of Management Information Systems, 29, 4 (2013), 217-248.

36. Taylor, Z. W. Speaking in tongues: Can international graduate students read international graduate admissions materials?. International Journal of Higher Education, 6, 3 (2017), 99-108.

37. Watson, D., \& Tellegen, A. Toward a consensual structure of mood. Psychological Bulletin, 98, 2 (1985), 219-235.

38. Yardi, S., \& Boyd, D. Tweeting from the Town Square: Measuring Geographic Local Networks. International AAAI Conference on Weblogs and Social Media, Washington DC, USA (2010).

39. Yasseri, T., Sumi, R., \& Kertész, J. Circadian patterns of wikipedia editorial activity: A demographic analysis. PloS one, 7, 1 (2012), e30091.

40. Zeitzer, J. M., Dijk, D. J., Kronauer, R. E., Brown, E. N., \& Czeisler, C. A. Sensitivity of the human circadian pacemaker to nocturnal light: melatonin phase resetting and suppression. The Journal of Physiology, 526, 3 (2000), 695-702. 